\title{
Intraocular pressure and ocular rigidity after LASIK
}

\author{
Pressão intraocular e rigidez ocular após LASIK
}

\author{
SebastiãoCronemberger ${ }^{1}$ \\ Cláudia Savassi Guimarães ${ }^{2}$ \\ Nassim Calixto $^{3}$ \\ José Márcio Fonseca Calixto ${ }^{4}$
}

\begin{tabular}{l} 
ABSTRACT \\
\hline Purpose: To assess the intraocular pressure (IOP) and ocular rigidity (E) \\
at $1,3,6$ and 24 postoperative months in eyes that underwent LASIK. \\
Methods: The IOP measured by Goldmann applanation tonometer (GAT) \\
and by the 5.5 and 10 gm. weights of a standardized Schioetz tonometer \\
(ST) and the E measured by differential tonometry (the 5.5 and 10 gm. of \\
ST) were assessed before and after LASIK (at 1, 3, 6 and 24 month) in 23 \\
eyes. The volume of the corneal indentation (Vc) and IOP with ST resting \\
on the eye (tonometric pressure - Pt) were also evaluated. Results: The \\
average IOP (GAT) at 6 and 24 months after LASIK was lower than at 1 \\
and 3 months and before LASIK. A statistically significant difference of \\
E was found at 1, 3, 6 and 24 months. The reduction of the central corneal \\
thickness (CCT) by LASIK was the cause of increasing values of Vc and \\
decreased values of Pt. In turn, the changes in Vc and Pt were responsible \\
for the lower IOP measurements by GAT and E changes. Conclusions: \\
LASIK reduces IOP readings by GAT but not the ones by ST (differential \\
tonometry). LASIK also diminishes E. IOP(GAT) values are lower at 6 and \\
24 months. IOP evaluation by ST is more accurate than that by GAT. At \\
6 months, Vc, Pt and E parameters are stabilized (no changes relatively \\
to 24 months measurements.
\end{tabular}

Keywords: Intraocular pressure/etiology; Keratomileusis, laser in situ/adverse effects

Trabalho realizado no Departamento de Oftalmologia da Universidade Federal de Minas Gerais - UFMG - Belo Horizonte (MG) - Brazil.

${ }^{1}$ Department of Ophthalmology, Faculty of Medicine, Universidade Federal de Minas Gerais - UFMG - Belo Horizonte (MG) - Brazil.

${ }^{2}$ Department of Ophthalmology, Faculdade de Ciências Médicas de Minas Gerais - FCMMG - Belo Horizonte (MG) - Brazil.

${ }^{3}$ Department of Ophthalmology, Faculty of Medicine UFMG - Belo Horizonte (MG) - Brazil.

${ }^{4}$ Department of Engineering of Structure, Universidade Federal de Minas Gerais - UFMG - Belo Horizonte (MG) - Brazil.

Author for correspondence: Sebastião Cronemberger Department of Ophthalmology, Faculty of Medicine UniversidadeFederal de Minas Gerais. Av. Alfredo Balena, 190 - S1. 3.005 - Belo Horizonte (MG) CEP 30130-100 E-mail: cronem@medicina.ufmg.br

Recebido para publicação em 08.10.2007

Última versão recebida em 06.05.2009

Aprovação em 21.05.2009

No author has a financial or proprietary interest in any material or method mentioned.

This paper was partially supported by FAPEMIG (Fundação de Amparo à Pesquisa do Estado de Minas Gerais). $\frac{\text { INTRODUCTION }}{\text { Laser refractive surgery (LRS) is a widely used procedure being its visual }}$ outcome well-known as good worldwide ${ }^{(1-2)}$. Many authors have found an artificial reduction of IOP measured by different types of tonometers in eyes that underwent $\operatorname{LRS}^{(3-6)}$. This is very important because false IOP values can delay the diagnosis of glaucoma or can interfere in the adequate control of the disease $^{(4)}$. E is an important physical parameter of the eye that expresses the resistance of eye layers to deformation ${ }^{(7-12)}$. In normal eyes, its average value is 0.0215 (with a variable range from 0.0060 to 0.0370$)^{(10-12)}$. Ametropias are the main factor that influences $\mathrm{E}^{(12)}$. Highly-myopic eyes have a low $\mathrm{E}$ whereas a high $\mathrm{E}$ is common in highly-hyperopic eyes ${ }^{(7)}$. $\mathrm{E}$ value remains relatively constant in the majority of patients, showing no relationship with gender and age. Taking into consideration that CCT is reduced after LRS, it arises the doubt if a thinner CCT can or can not compromises E. Another question to be answered is how and why the IOP measurements are affected.

Therefore, the purpose of this paper is to assess the IOP and the E after LASIK and try to answer how and why the IOP measurement is affected after this surgery.

To our knowledge, this is the first paper in the literature that uses ST to evaluate IOP and E after LASIK. 


\section{METHODS}

The IOP and the E before and at 1, 3, 6 and 24 postoperative months of 23 eyes with myopia associated or not to astigmatism that underwent LASIK were evaluated. All eyes presented: best corrected visual acuity equal to or higher than 20/40, stable refraction, normal corneal topography (ORBSCAN, Bausch \& Lomb Optical Co, Rochester, NY, USA), CCT measured with an ultrasonic pachymeter (model 5100e; DGH Technology, Exton, PA) equal to or higher than $480 \mu \mathrm{m}$; normal eye fundus and IOP equal to or lower than $18 \mathrm{mmHg}$ (GAT) before LASIK. The recorded CCT was the average of three consecutives measurements. The study was performed according to the tenets of the Declaration of Helsinki and approved by the investigational review board of the Federal University of Minas Gerais. All subjects included in the study were informed of the purpose of the research and the procedures to be used in collecting the data, and all provided written informed consent. All patients were submitted, within three days before LASIK, to the following exams: three CCT measurements, IOP measurement by GAT at the slit lamp followed by indentation tonometry with ST (Sklar model) with the patient in supine position (without pillow). ST was previously standardized at the tonometer's station of our Service. Only one IOP measurement respectively and sequentially with 5.5 and $10 \mathrm{gm}$. weights of ST was performed for each patient. It was given an interval of at least two minutes among the measurements. In all patients LASIK was performed by third year residents under the supervision of an expert refractive surgeon. In all patients, the Nidek EC-5000 (Nidek CO, Ltd) was used. The same surgical technique was performed in all eyes and consisted of one flap of $160 \mu \mathrm{m}$ using the LASIK-One microkeratome, suction ring of $9.5 \mathrm{~mm}$ and laser application on an optic zone of 5.0 and $6.0 \mathrm{~mm}$ diameter. The amount of corneal ablation changed according to the dioptric value to be corrected. LASIK was completed without complication in all cases. In the postoperative period, all patients received topically the association of $0.3 \%$ tobramicine and $0.1 \%$ dexamethasone q.i.d for seven days and ocular surface lubricant drops six times a day for 30 days. At 1, 3, 6 and 24 months after LASIK, all parameters were again measured by the same way and sequence as it was done before LASIK. All measurements were taken by the same examiner (SC) at the same time of day (around 9:00 A.M.), to eliminate any possible diurnal variation. The Friedenwald's tables $(1955)^{(9-10)}$ were used to calculate the pre and postoperative averages and standard deviations of IOP, E, Vc and Pt by differential tonometry. The Student's paired t-test was used to compare the differences among the pre and postoperative averages of all studied parameters. The level of significance was set at $5 \%$.

\section{RESULTS}

Data from 23 eyes (13 patients) were analyzed pre and postoperatively at 1, 3, 6 and 24 months. The average age of the patients was 37.8 years (range from 23 to 54 year-old). Five (32\%) patients were male and eight $(68 \%)$ female. Ten $(77 \%)$ patients were caucasian; two (15\%) black and one (8\%) mulatto. Ten patients underwent LASIK in both eyes and three patients in only one eye: before LASIK, the spherical equivalent of the 23 eyes ranged form -1.00 to -9.00 diopters (average \pm SD: $-3.75 \pm 2.5$ diopters). The amount of corneal ablation which was related to the corrected value of refraction error ranged from 15.0 to $100.3 \mu \mathrm{m}$ (average $\pm \mathrm{SD}: 48.2 \pm 27.0 \mu \mathrm{m}$ ). The average CCT was reduced from $533.0 \pm 29.3 \mu \mathrm{m}$, preoperatively, to $492.9 \pm 25.4 \mu \mathrm{m}, 492.7 \pm 25.3 \mu \mathrm{m}$ and $492.7 \pm 20.43 \mu \mathrm{m}$ respectively at 1, 3 and 6 months after LASIK. Tables 1-5 show the average and standard deviation values of IOP measurements (GAT and ST) and Vc, Pt and E pre and postoperatively (at 1, 3, 6 and 24 months). The IOP values (GAT) diminished gradually being lower and less variable at 6 and 24 months

\begin{tabular}{|c|c|c|c|c|c|c|c|c|c|c|}
\hline & \multicolumn{2}{|c|}{ Preoperative } & \multicolumn{2}{|c|}{30 days } & \multicolumn{2}{|c|}{90 days } & \multicolumn{2}{|c|}{180 days } & \multicolumn{2}{|c|}{720 days } \\
\hline & OD & OS & OD & OS & OD & OS & OD & $\overline{O S}$ & OD & OS \\
\hline Average & 13.00 & 13.50 & 12.60 & 12.70 & 12.10 & 11.60 & 10.50 & 10.20 & 10.50 & 10.80 \\
\hline SD & 2.95 & 3.12 & 3.53 & 3.31 & 3.42 & 3.61 & 2.51 & 1.81 & 2.22 & 1.89 \\
\hline$t$ & & & 0.46 & 0.87 & 0.88 & 1.70 & $3.17^{*}$ & $5.49^{*}$ & $3.13^{*}$ & $4.34^{*}$ \\
\hline
\end{tabular}

\begin{tabular}{|c|c|c|c|c|c|c|c|c|c|c|}
\hline & \multicolumn{2}{|c|}{ Preoperative } & \multicolumn{2}{|c|}{30 days } & \multicolumn{2}{|c|}{90 days } & \multicolumn{2}{|c|}{180 days } & \multicolumn{2}{|c|}{720 days } \\
\hline & OD & OS & OD & OS & OD & OS & OD & OS & OD & OS \\
\hline Average & 19.00 & 20.00 & 23.00 & 23.00 & 22.00 & 22.00 & 20.00 & 18.00 & 21.00 & 21.00 \\
\hline SD & 3.03 & 2.61 & 4.48 & 5.14 & 5.12 & 3.88 & 4.32 & 3.50 & 4.01 & 4.98 \\
\hline $\mathrm{t}$ & & & $-2.81^{*}$ & -1.48 & -1.92 & -1.49 & -0.68 & -1.50 & -1.33 & -1.35 \\
\hline
\end{tabular}


after LASIK with a statistically significant difference in relation to the preoperative values. However, no statistically significant difference in all postoperative periods (1, 3, 6 and 24 months) was found when IOP was evaluated using the 5.5 and $10 \mathrm{gm}$. weights of ST (differential tonometry). We also calculated the differences between the pre and postoperative average and standard deviation of $\mathrm{Vc}$ and $\mathrm{Pt}$ using the 5.5 and $10 \mathrm{gm}$. weights of ST. Both parameters have changed (increase of $\mathrm{Vc}$ and reduction of $\mathrm{Pt}$ ) being the differences statistically significant at 1, 3, 6 and 24 months $(\mathrm{Vc})$ and at 1 and 3 months $(\mathrm{Pt})$. These findings show that the reduction of CCT carried out by LASIK reduces the corneal resistance to the deformation and, in consequence, there are respectively a statistically significant increase of $\mathrm{Vc}$ values and a decrease of $\mathrm{Pt}$ values. Table 5 shows that $\mathrm{E}$ diminishes significantly at 1, 3, 6 and 24 months. Using the Friedenwald's equation ( $\log \mathrm{Po}=\mathrm{Log} \mathrm{Pt}-$ E. Vc) it can be noted that the circumstances of the indentation tonometry (ST) are completely different from that of GAT. $\mathrm{Pt}$ is a basic data for tonometer calibration and it is the pressure inside the eye when ST is resting on it. In indentation tonometry, the IOP is quite different without the tonometer but in applanation tonometry (GAT) the IOP is equal to $0.98 \mathrm{Pt}$. The underestimation of IOP (GAT) is fundamentally related to the change in the corneal structure (fragmentation or rupture of Bowman's membrane) and reduction of the corneal thickness decreasing the corneal resistance to deformation. The corneal deformation in applanation tonometry is the same pre and post LASIK but the corneal resistance is surely reduced by LASIK and, therefore, also contributing for lower values obtained by applanation tonometry besides the invalidation of the fundamental principle of applanation (integrity of Bowman's membrane). GAT is, by principle, unable to compensate the corneal changes induced by LASIK but the differential tonometry (ST) is able to register those changes and, surely to compensate them giving the correct values in reading the IOP. No complications arising from the use of the tonometers and ultrasonic pachymeter were recorded.

\section{DISCUSSION}

LRS (PRK or LASIK) is a safe procedure with good visual outcomes ${ }^{(1)}$. The aim of both types of LRS is to correct ametropias through the reduction of CCT. In the literature, some authors have reported complications of LRS that occurred in consequence of ocular trauma ${ }^{(1-2)}$. However, since the beginning of the LRS, initially PRK and further LASIK, there is no consensus if the eyes that underwent these surgeries remain with the same resistance or if they become less resistant to surgical trauma. In other words, could those kinds of surgery change E? Another question that arises is why the values of IOP (GAT) measurements are lower after LRS than before it? This paper

\begin{tabular}{|c|c|c|c|c|c|c|c|c|c|c|}
\hline & \multicolumn{2}{|c|}{ Preoperative } & \multicolumn{2}{|c|}{30 days } & \multicolumn{2}{|c|}{90 days } & \multicolumn{2}{|c|}{180 days } & \multicolumn{2}{|c|}{720 days } \\
\hline & OD & OS & OD & OS & OD & OS & OD & OS & OD & OS \\
\hline Average & 6.473 & 6.283 & 7.964 & 7.925 & 8.727 & 8.650 & 8.973 & 8.058 & 8.373 & 8.278 \\
\hline SD & 1.460 & 1.431 & 2.513 & 2.064 & 1.658 & 1.786 & 2.253 & 1.706 & 2.905 & 2.976 \\
\hline $\mathrm{t}$ & & & $-2.992^{*}$ & $-3.501^{*}$ & $-4.800^{*}$ & $-4.580^{*}$ & $-4.960^{*}$ & $-3.370^{*}$ & $-2.950^{*}$ & $-2.680^{*}$ \\
\hline
\end{tabular}

\begin{tabular}{|c|c|c|c|c|c|c|c|c|c|c|}
\hline & \multicolumn{2}{|c|}{ Preoperative } & \multicolumn{2}{|c|}{30 days } & \multicolumn{2}{|c|}{90 days } & \multicolumn{2}{|c|}{180 days } & \multicolumn{2}{|c|}{720 days } \\
\hline & OD & OS & OD & OS & OD & OS & OD & $\overline{\text { OS }}$ & OD & OS \\
\hline Average & 0.115 & 0.115 & 0.102 & 0.102 & 0.097 & 0.098 & 0.104 & 0.115 & 0.102 & 0.101 \\
\hline SD & 0.014 & 0.013 & 0.014 & 0.103 & 0.022 & 0.017 & 0.023 & 0.015 & 0.021 & 0.033 \\
\hline $\mathrm{t}$ & & & $5.390^{*}$ & $-3.750^{*}$ & $2.460^{*}$ & $2.650^{*}$ & 1.520 & -0.060 & 2.054 & 1.630 \\
\hline
\end{tabular}

\begin{tabular}{|c|c|c|c|c|c|c|c|c|c|c|}
\hline & \multicolumn{2}{|c|}{ Preoperative } & \multicolumn{2}{|c|}{30 days } & \multicolumn{2}{|c|}{90 days } & \multicolumn{2}{|c|}{180 days } & \multicolumn{2}{|c|}{720 days } \\
\hline & OD & OS & OD & $\overline{\text { OS }}$ & OD & OS & OD & OS & OD & OS \\
\hline Average & 0.019 & 0.020 & 0.014 & 0.014 & 0.012 & 0.012 & 0.013 & 0.015 & 0.014 & 0.014 \\
\hline SD & 0.006 & 0.007 & 0.006 & 0.005 & 0.005 & 0.003 & 0.005 & 0.005 & 0.006 & 0.007 \\
\hline$t$ & & & $3.903^{*}$ & $4.122^{*}$ & $3.186^{*}$ & $3.601^{*}$ & $3.845^{*}$ & 2.000 & $2.540^{*}$ & $2.590^{*}$ \\
\hline
\end{tabular}


tries to answer the questions. One point to be emphasized is that because of the reduction of CCT and also of the corneal curvature change, the artificial reduction of IOP measurement can occur with any kind of applanation tonometer, mainly with GAT which is still considered the gold standard ${ }^{(5)}$.

For statistical analysis, both eyes of the same patient were considered because: 1 . both eyes of some patients did not have the same preoperative dioptric value; 2 . the amount of corneal ablation and resulting fragmentation or rupture of Bowman's membrane were not the same in both eyes; 3 . each eye of a patient could have a different postoperative behavior.

In agreement with the values reported by other authors ${ }^{(3,5-6)}$, our results showed an average artificial reduction of IOP measurement equal to $0.4,0.9,2.5$ and $2.5 \mathrm{mmHg}$ respectively at 1 , 3,6 and 24 months in the right eye and equal to $0.6,1.7,3.3$ and $2.7 \mathrm{mmHg}$ respectively at 1, 3,6 and 24 months in the left eye after LASIK (Table 1). The differences were not statistically significant at 1 and 3 months. However, they were statistically significant after 6 and 24 months. In relation to $\mathrm{E}$ the results showed that it reduces significantly at 1, 3, 6 and 24 months (Table 5). E evaluation is more accurate by the differential method (two weights) because changes in Vc and Pt are significantly higher than in the combined method (Vc and Pt changes are minimal in applanation: $\mathrm{IOP}=0.98 \mathrm{Pt}$ and $\mathrm{Vc}=0.44 \mu \mathrm{l}$ ). The calculated $\mathrm{E}$ values were smaller; the sclera presented smaller resistance to deformation because the eyes were myopic in this study. Some authors ${ }^{(1)}$ have reported that the refractive stabilization after LASIK occurs up to 90 days. In this paper, it is important to emphasize that the lowest averages of IOP (GAT) were found at 6 months with a statistical difference highly significant (Table 1). No statistically significant difference was found comparing the parameters between 6 and 24 months. So, after 6 months (not 3 months), there was a stabilization of the measured values (IOP, Vc, Pt and E). These findings are very important because of the following reasons: 1. the great majority of patients that have undergone LRS are relatively young and myopic as the ones herein studied (average age of 37.8 years) and, in consequence, they are outside of the age-group in which the glaucoma prevalence is higher; 2. so far, there is no preoperative predictive factor of the IOP measurement value reduction magnitude; 3 . to date, no factor used for CCT in IOP measurements has been completely satisfactory ${ }^{(12)}$; 4. nobody knows yet the profile of the value of IOP measurement in the daily IOP curve in eyes that underwent LRS. It is obvious that the real IOP does not change in consequence of LASIK. Therefore, it is necessary to be very careful in selecting the patients who are candidates to LRS and to know very carefully the basic value of IOP before any kind of corneal surgery. Moreover, for all above-mentioned reasons LRS is not recommended in suspected or glaucomatous patients.

Recently, one paper ${ }^{(13)}$ showed that the values of IOP measurements obtained by the pneumotonometer are lower after LASIK than those found after PRK, suggesting that some interlamellar scarring could occur during the first year after LASIK. Corneal hysteresis $(\mathrm{CH})$ and corneal resistance factor (CRF) measured by the ocular response analyzer (ORA) are novel methods of analyzing corneal elasticity (damping factor). According to some papers, hysteresis of the cornea is also reduced after $\operatorname{LRS}^{(14-16)}$. Therefore, it is possible that after LASIK (reducing CCT), E is also diminished in consequence of the reduction of $\mathrm{CH}$ and $\mathrm{CRF}$. In a more recent study ${ }^{(16)} \mathrm{IOP}$ was measured on 66 myopic eyes by GAT, ORA, and DCT before and one week after LASIK. The IOP measurement taken with DCT seems to be relatively immune to changes in corneal biomechanics and pachymetry after LASIK, in comparison to GAT and ORA measurements of IOP. LASIK produced a marked decline in $\mathrm{CH}$ and $\mathrm{CRF}$, which may reflect respectively changes in the viscous and elastic qualities of the post-LASIK cornea. Differently of the present study with a long-term follow-up ( 24 months), the follow-up of IOP measures of that study ${ }^{(16)}$ was only of one week. At last, this paper confirms the data presented by one of us $(\mathrm{NC})^{(8,12)}$ in which the IOP was always higher when measured by ST than by GAT. At the pre-operative period, the average IOP value by GAT was $13.00 \mathrm{mmHg}$ (OD) and $13.50 \mathrm{mmHg}$ (OS) whereas it was $19 \mathrm{mmHg}$ (OD) and $20 \mathrm{mmHg}$ (OS) by ST.

Despite the limitations placed by the small sample of the examined cases, we have demonstrated that LASIK causes: 1. increase in Vc values; 2. decrease in $\mathrm{Pt}$ and 3. reduction of $\mathrm{E}$.

\section{CONCLUSIONS}

The cornea becomes less resistant after LASIK and, in consequence, the GAT falsely underestimates the IOP.

IOP evaluation by ST is more accurate than that by GAT.

\section{RESUMO}

Objetivo: Avaliar comparativamente a pressão intraocular ( $\mathrm{Po})$ e a rigidez ocular (E) antes e após 1, 3, 6 e 24 meses em olhos submetidos a LASIK. Métodos: Foram avaliados a Po (pela tonometria de aplanação de Goldmann - TAG e pela tonometria diferencial com os pesos 5,5 e $10 \mathrm{~g}$ do tonômetro de Schioetz (ST) e E (pela tonometria diferencial) antes e após 1, 3, 6 e 24 meses em 23 olhos submetidos a LASIK. Foram também avaliados o volume de depressão corneana $(\mathrm{Vc})$ e a pressão tonométrica $(\mathrm{Pt})$ com o tonômetro de Schioetz repousando sobre o olho. Resultados: Os valores médios da Po (TAG) 6 e 24 meses após o LASIK foram menores que os obtidos antes e 1 e 3 meses após o LASIK. Os valores médios de E foram significativamente inferiores após 1, 3, 6 e 24 meses após o LASIK que antes da cirurgia. A redução da espessura central da córnea pelo LASIK causou aumento dos valores médios de Vc e diminuição dos de Pt. Por sua vez, essas alterações de Vc e Pt foram as responsáveis pelos menores valores das medidas de Po (TAG) e de E. Conclusões: A cirurgia por LASIK diminui os valores da leitura da Po medida pelo tonômetro de Goldmann, porém não altera os 
valores de Po obtidos pela tonometria de Schioetz. A cirurgia também diminui a rigidez ocular. As medidas da Po (TAG) apresentaram menores valores 6 e 24 meses após o LASIK. A avaliação da Po pelo ST parece ser mais confiável que pelo TAG. Observou-se estabilização dos valores de Vc, Pt and E seis meses após o LASIK.

Descritores: Pressão intraocular/etiologia; Ceratomileuse assistida por excimer laser in situ/efeitos adversos

\section{REFERENCES}

1. Sugar A, Rapuano CJ, Culbertson WW, Huang D, Varley GA, Agapitos PJ, et al. Laser in situ keratomileusis for myopia and astigmatism: safety and efficacy: a report by the American Academy of Ophthalmology. Ophthalmology. 2002; 109(1): 175-87.

2. Alves MR, Chamon W, Nosé W, editores. Cirurgia refrativa. Rio de Janeiro: Cultura Médica; 2003.

3. Moura CR, Paranhos Júnior A, Grottone GT, Almeida PB, Mello PAA, Prata Júnior JA. Análise da pressão intraocular após ceratectomia fotorrefrativa com excimer laser. Arq Bras Oftalmol. 2000;63(2):107-10.

4. Costa VP. Glaucoma e cirurgia refrativa. Rev Bras Oftalmol. 2001;60(11):767-8.

5. Shinzato GT. Avaliação da pressão intraocular com os tonômetros de não-contato, tono-pen e de Goldmann em olhos submetidos a Lasik para correção refrativa de miopia e astigmatismo miópico [tese]. Belo Horizonte: Universidade Federal de Minas Gerais; 2000.

6. Fontes BM, Navajas EV, Melo Júnior LAS, Fontes MLM, Fontes PC. Altera- ção da pressão intraocular aferida pela tonometria de aplanação após laser in situ keratomileusis. Rev Bras Oftalmol. 2004;63(5/6):315-20.

7. Drance SM. The coefficient of scleral rigidity in normal and glaucomatous eyes. Arch Ophthalmol. 1960;63:668-74.

8. Calixto N. Tonometria (aplanação versus impressão) e coeficiente de rigidez escleral. Rev Bras Oftalmol. 1961;20:49-72.

9. Friedenwald JS. Tonometer calibration; an attempt to remove discrepancies found in the 1954 calibration scale for Schioetz tonometers. Trans Am Acad Ophthalmol Otolaryngol. 1957;61(1):108-22.

10. Friedenwald JS. Contribution to the Ttheory and practice of tonometry. Am J Ophthalmol. 1937;20:985-1024.

11. Calixto NS. Pressão intraocular, curva diária de pressão intraocular, rigidez parietal, coeficientes tonográficos. Médias de normalidades em diferentes grupos etários. (tese - Livre docência). Belo Horizonte: Universidade Federal de Minas Gerais; 1967.

12. Calixto NS. Examen funcional del ojo miope no glaucomatoso. In: II Simpósio Sudamericano de Glaucoma, 1980, Iguaçú/Brasil. Anais do II Simpósio Sudamericano de Glaucoma; 1980. v.1. p.84-97.

13. Hjortdal JO, Moller-Pedersen T, Ivarsen A, Ehlers N. Corneal power, thickness, and stiffness: Results of a prospective randomized controlled trial of PRK and LASIK for myopia. J Cataract Refract Surg. 2005;31(1):21-9.

14. Martinez-de-la-Casa JM, Garcia-Feijoo J, Fernandez-Vidal A, Mendez-Hernandez C, Garcia-Sanchez J. Ocular response analyzer versus Goldmann applanation tonometry for intraocular pressure measurements. Invest Ophthalmol Vis Sci. 2006;47(10):4410-4.

15. Kirwan C, O'Keefe M, Lanigan B. Corneal hysteresis and intraocular pressure measurement in children using the reichert ocular response analyzer. Am J Ophthalmol. 2006;142(6):990-2. Erratum in: Am J Ophthalmol. 2007;144(4):642.

16. Pepose JS, Feigenbaum SK, Qazi MA, Sanderson JP, Roberts CJ. Changes in corneal biomechanics and intraocular pressure following LASIK using static, dynamic, and noncontact tonometry. Am J Ophthalmol. 2007;143(1):39-47. 